\title{
Is Telemedicine our cup of tea? A nationwide cross-sectional survey regarding doctors' experience and perceptions
}

\author{
Laima Alam¹, Mafaza Alam², \\ Amina Mannan Malik ${ }^{3}$, Varqa Faraid ${ }^{4}$
}

\begin{abstract}
Objectives: To evaluate the experience and perceptions regarding Telemedicine and the perceived barriers among medical doctors.

Methods: This cross-sectional survey was carried out by enrolling practicing doctors of Pakistan with experience of $\geq 6$ months by sending a validated and piloted questionnaire through email. Data collection was done from $10^{\text {th }}$ October to 9th November 2020 after taking ethical approval from the concerned authorities. Data was analysed using SPSS v. 19.0.

Results: Two-hundred-forty responses were received with a response rate of $63 \%$. Female participants $(62.8 \%)$ were in majority and most of the participants were working in urban $(88.5 \%)$ or semi-urban $(9 \%)$ locality in either teaching (35.9\%) or tertiary care hospitals (34.6\%). Seventy-three percent of the doctors didn't receive formal training with more than half of the doctors reporting non-availability of infrastructure and specific hardware. A large number of the participants were concerned regarding the non-availability of regulatory bodies, evaluations and accreditations of the service providers, the risks of malpractice, missed-diagnosis, prescription errors and medico-legal issues. The availability of specific infrastructure was statistically related to the hospital setup, locality and the specialty of the participants. Lack of technological literacy and infrastructure were considered the main constraints for the public in using telemedicine.

Conclusion: Evidence of effectiveness of telemedicine across different fields is inconsistent and lacks technical, legal, cultural and ethical considerations. Inadequate training, low level of technological literacy and lack of infrastructure are the main barriers in implementing tele-health. High-quality evidence based studies are required for practical and long-term policies.
\end{abstract}

KEYWORDS: Chronic disease, Developing countries, Infrastructure, Survey, Telemedicine.

doi: https://doi.org/10.12669/pjms.37.5.3970

How to cite this:

Alam L, Alam M, Malik AM, Faraid V. Is Telemedicine our cup of tea? A nationwide cross-sectional survey regarding doctors' experience and perceptions. Pak J Med Sci. 2021;37(5):1319-1325. doi: https://doi.org/10.12669/pjms.37.5.3970

This is an Open Access article distributed under the terms of the Creative Commons Attribution License (http://creativecommons.org/licenses/by/3.0), which permits unrestricted use, distribution, and reproduction in any medium, provided the original work is properly cited.

\section{INTRODUCTION}

Healthcare, being a rapidly evolving field, requires economical, efficacious with good

Correspondence:

Laima Alam, FCPS,

Consultant Gastroenterology,

Bahria Town International Hospital, Phase VIII,

Rawalpindi, Pakistan.

E-mail: Laima_alam@yahoo.com

* Received for Publication:

* Revision Received:

* Revision Accepted:
December 5, 2020

March 29, 2021

April 5, 2021 reproducibility, practical and high-quality solutions for optimal patient care on individual as well as communal levels. ${ }^{1}$ Telemedicine, though not a recent entity in the medical field, has been hailed as a billion dollars industry with further potential to improve and expand. Telemedicine has aroused interest in the international markets due to its ability to overcome barriers in the way of assessing quality healthcare. ${ }^{2}$

Telemedicine includes services like teleconsultation, tele-monitoring, tele-counseling, tele-education, tele-care, tele-psychiatry and telerehabilitation that can serve clients remotely and 
widely. ${ }^{1}$ Distant healthcare can be used to realign chronic disease management for easy availability of quality care with less in-person hospital visits and cost-effective health modules. ${ }^{3}$

Pakistan, being a predominantly developing country, lags far behind in formulating and implementing sustainable healthcare policies. ${ }^{4}$ Despite being a concomitant commodity to conventional healthcare in developed countries, comparatively lesser efforts are done for similar utilities in the third world countries. ${ }^{5}$ Lesser return of investment (ROI), socio-economic barriers, poor adaptability and the unavailability of proper technological infrastructures are some of the local and international hurdles. ${ }^{5}$

Multiple research papers are available regarding the need for telemedicine and the "knowledgeattitude-practices" studies encompassing doctors but none have been formulated to assess the reason for reluctance towards implementing telemedicine in Pakistan. In this nationwide crosssectional survey we tried to evaluate the ground realities responsible for poor acceptability of Telemedicine among doctors and the perceived barriers making this novel healthcare technology a failure.

\section{METHODS}

This cross-sectional survey was carried out by enrolling practicing doctors working in Pakistan with clinical experience of $\geq 6$ months through convenience sampling after acquiring ethical approval from the concerned department (905/ Trg-ABP1K2 dated 1/10/2020). The participants were encouraged to share the survey through social-media for maximum participation. The survey was completed in one month i.e; from $10^{\text {th }}$ October to 9th November 2020. The questionnaire was developed by authors after relevant literature review. ${ }^{4-8}$ It was reviewed by two medical education experts for content validity. The survey was piloted among 10 doctors before putting it to test. The questionnaire was sent through email, a reminder was given to the participants after one week of no response and the candidates were dropped who failed to respond after another seven days.

The questionnaire consisted of three parts; demographics with availability of basic infrastructure for tele-health services, 17 questions evaluating the general perception and experience of telemedicine with a five-point Likert scale and the perceived barriers at public level.
Table-I: Demographics and availability of basic infrastructure of telemedicine $(n=234)$.

\begin{tabular}{|c|c|c|}
\hline Variables & Frequency $(\%)$ & Pvalue \\
\hline \multicolumn{3}{|l|}{ Gender } \\
\hline Male & $87(37.2)$ & \multirow[t]{2}{*}{$\leq 0.001$} \\
\hline Female & $147(62.8)$ & \\
\hline \multicolumn{3}{|l|}{ Age (years) } \\
\hline$\leq 30$ & $153(65.4)$ & \multirow[t]{4}{*}{$\leq 0.001$} \\
\hline $31-40$ & $66(28.2)$ & \\
\hline $41-50$ & $12(5.1)$ & \\
\hline$>50$ & $3(1.3)$ & \\
\hline \multicolumn{3}{|l|}{ Experience (years) } \\
\hline$<1$ & $30(12.8)$ & \multirow{5}{*}{$\leq 0.001$} \\
\hline $1-3$ & $102(43.6)$ & \\
\hline $4-6$ & $45(19.2)$ & \\
\hline $7-9$ & $30(12.8)$ & \\
\hline$\geq 10$ & 27(11.5) & \\
\hline \multicolumn{3}{|l|}{ Locality } \\
\hline Rural & $6(2.6)$ & \multirow{3}{*}{$\leq 0.001$} \\
\hline Urban & $207(88.5)$ & \\
\hline Semi-urban & $21(9)$ & \\
\hline \multicolumn{3}{|l|}{ Work setup } \\
\hline Private clinic & $36(15.4)$ & \multirow{5}{*}{$\leq 0.001$} \\
\hline Primary healthcare & $15(6.4)$ & \\
\hline District hospital & $18(7.7)$ & \\
\hline Tertiary care hospital & $81(34.6)$ & \\
\hline Teaching hospital & $84(35.9)$ & \\
\hline \multicolumn{3}{|c|}{ Telemedicine specific training } \\
\hline Yes & $48(20.5)$ & \multirow{3}{*}{$\leq 0.001$} \\
\hline No & 171(73.1) & \\
\hline Don't know & $15(6.4)$ & \\
\hline \multicolumn{3}{|c|}{ Availability of infrastructure } \\
\hline Yes & $75(32.1)$ & \multirow{3}{*}{$\leq 0.001$} \\
\hline No & $123(52.6)$ & \\
\hline Don't know & $36(15.4)$ & \\
\hline \multicolumn{3}{|c|}{ Availability of specific hardware } \\
\hline Yes & $63(26.9)$ & \multirow{3}{*}{$\leq 0.001$} \\
\hline No & $150(64.1)$ & \\
\hline Don't know & $21(9)$ & \\
\hline \multicolumn{3}{|c|}{ Availability of specific software } \\
\hline Yes & $138(59)$ & \multirow{3}{*}{$\leq 0.001$} \\
\hline No & $63(26.9)$ & \\
\hline Don't know & $33(14.1)$ & \\
\hline \multicolumn{3}{|l|}{ Affordability for the setup } \\
\hline Yes & $138(59)$ & \multirow{3}{*}{$\leq 0.001$} \\
\hline No & $45(19.2)$ & \\
\hline Don't know & $51(21.8)$ & \\
\hline Affordability for the pati & & \\
\hline Yes & $120(51.3)$ & \\
\hline No & $57(24.4)$ & $\leq 0.001$ \\
\hline Don't know & $57(24.4)$ & \\
\hline Means to measure effecti & ss of telemedici & \\
\hline Yes & $84(35.9)$ & \\
\hline No & $99(42.3)$ & \\
\hline Don't know & $51(21.8)$ & \\
\hline Need for physical examin & & \\
\hline Yes & 213(91) & $\leq 0.001$ \\
\hline No & $21(9)$ & \\
\hline
\end{tabular}


The sample size was calculated with margin of error set at 5\%, confidence level at $95 \%$ and an anticipated frequency (response distribution) of $50 \%$ using OpenEpi sample size calculator. To measure the internal consistency of the instrument, Cronbach's alpha was calculated which produced a value of 0.86. Data was statistically described in terms of frequencies and percentages. Chi square test and Fisher exact test were used to compare qualitative data. All statistical analyses were performed using SPSS v 19.0. All $\mathrm{p}$ values $\leq 0.05$ were considered statistically significant.

\section{RESULTS}

A total of 380 questionnaires were sent, out of which 240 surveys were received back, making a response rate of $63 \%$. Two-hundred-thirty four surveys were complete and the six incomplete responses were discarded. The distribution of specialties and cities/districts is shown in Fig.1. Female participants $(62.8 \%)$ were in majority and most of the participants were working in urban $(88.5 \%)$ or semi-urban $(9 \%)$ locality in either teaching $(35.9 \%)$ or tertiary care hospitals $(34.6 \%)$. Seventy-three percent of the doctors didn't receive formal telemedicine training with more than half of the doctors reporting non-availability of infrastructure and specific hardware (Table-I).

A large number of the participants were concerned regarding the non-availability of regulatory bodies, evaluations and accreditations of the service providers, the risks of malpractice, missed-diagnosis, prescription errors and medico-legal issues (Table-II). The availability of specific infrastructure and necessary equipment was statistically related to the hospital setup, locality and the specialty of the participating doctors (Table-III) with smaller hospitals/ clinics running at primary healthcare level being severely deficient in all facilities. The perceived affordability of tele-health services was also statistically related to the specialty of the participating doctors and their work set-up.

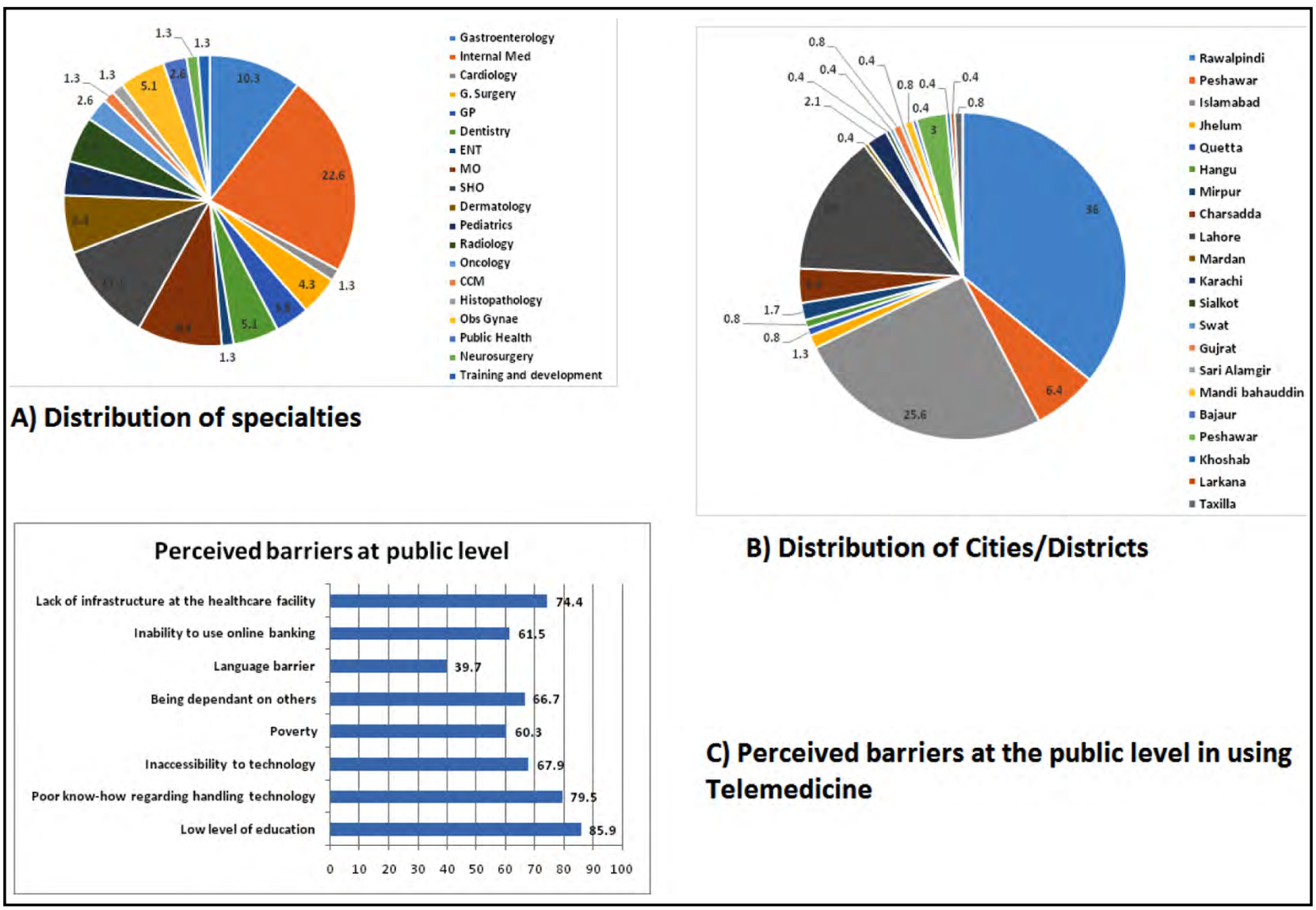

Fig.1: Distribution of participants according to location and medical specialty (A-B).

Perceived barriers to the acceptability of telemedicine at public level (C). 
Laima Alam et al.

Table-II: Evaluation of telemedicine services using a five-point scale.

\begin{tabular}{|c|c|c|c|c|c|c|}
\hline Survey questions & $\begin{array}{l}\text { Strongly } \\
\text { agree }\end{array}$ & Agree & Don't know & Disagree & $\begin{array}{l}\text { Strongly } \\
\text { disagree }\end{array}$ & $p$ \\
\hline $\begin{array}{l}\text { Do you believe telemedicine set up is } \\
\text { expensive? }\end{array}$ & $9(3.8)$ & $27(11.5)$ & $120(51.3)$ & $45(19.2)$ & $33(14.1)$ & $\leq 0.001$ \\
\hline $\begin{array}{l}\text { Do you believe telemedicine has high } \\
\text { cost of maintenance? }\end{array}$ & $21(9)$ & $39(16.7)$ & $108(46.2)$ & $45(19.2)$ & $21(9)$ & $\leq 0.001$ \\
\hline $\begin{array}{l}\text { Do you believe your society has a high } \\
\text { resistance to change? }\end{array}$ & $90(38.5)$ & $69(29.5)$ & $51(21.8)$ & $12(5.1)$ & $12(5.1)$ & $\leq 0.001$ \\
\hline $\begin{array}{l}\text { Do you believe there is unavailability of } \\
\text { required infrastructure for telemedicine? }\end{array}$ & $63(26.9)$ & $78(33.3)$ & $60(25.6)$ & $24(10.3)$ & $9(3.8)$ & $\leq 0.001$ \\
\hline $\begin{array}{l}\text { Do you believe there is lack of } \\
\text { standard for comparison while using } \\
\text { telemedicine? }\end{array}$ & $81(34.6)$ & $54(23.1)$ & $72(30.8)$ & $12(5.1)$ & $15(6.4)$ & $\leq 0.001$ \\
\hline $\begin{array}{l}\text { Do you believe there is lack of regulatory } \\
\text { bodies for telemedicine? }\end{array}$ & $87(37.2)$ & $72(30.8)$ & $48(20.5)$ & $18(7.7)$ & $9(3.8)$ & $\leq 0.001$ \\
\hline $\begin{array}{l}\text { Do you believe there is lack of common } \\
\text { care protocol for telemedicine? }\end{array}$ & $48(20.5)$ & $84(35.9)$ & $72(30.8)$ & $15(6.4)$ & $15(6.4)$ & $\leq 0.001$ \\
\hline $\begin{array}{l}\text { Do you believe there is lack of } \\
\text { accreditation of service providers } \\
\text { (evaluate, validate, certify)? }\end{array}$ & 63(26.9) & $57(24.4)$ & $84(35.9)$ & $21(9)$ & $9(3.8)$ & $\leq 0.001$ \\
\hline $\begin{array}{l}\text { Do you believe there is lack of } \\
\text { regulations to avoid malpractice? }\end{array}$ & $99(42.3)$ & $63(26.9)$ & $51(21.8)$ & $6(2.6)$ & $15(6.4)$ & $\leq 0.001$ \\
\hline $\begin{array}{l}\text { Do you believe your practice of } \\
\text { telemedicine would be covered by your } \\
\text { indemnity? }\end{array}$ & $21(9)$ & $42(17.9)$ & $75(32.1)$ & $45(19.2)$ & $51(21.8)$ & $\leq 0.001$ \\
\hline $\begin{array}{l}\text { Do you believe there is lack of user } \\
\text { friendly interface? }\end{array}$ & $48(20.5)$ & $78(33.3)$ & $72(30.8)$ & $24(10.3)$ & $12(5.1)$ & $\leq 0.001$ \\
\hline $\begin{array}{l}\text { Do you believe there would a risk to } \\
\text { privacy and confidentiality? }\end{array}$ & 42(17.9) & $69(29.5)$ & $78(33.3)$ & $33(14.1)$ & $12(5.1)$ & $\leq 0.001$ \\
\hline $\begin{array}{l}\text { Are you concerned about missed } \\
\text { diagnosis? }\end{array}$ & 102(43.6) & $84(35.9)$ & $24(10.3)$ & $15(6.4)$ & $9(3.8)$ & $\leq 0.001$ \\
\hline $\begin{array}{l}\text { Are you concerned about medico-legal } \\
\text { issues? }\end{array}$ & 102(43.6) & $51(21.8)$ & $42(17.9)$ & $30(12.8)$ & $9(3.8)$ & $\leq 0.001$ \\
\hline $\begin{array}{l}\text { Are you concerned about prescription } \\
\text { errors? }\end{array}$ & $60(25.6)$ & $87(37.2)$ & $57(24.4)$ & $24(10.3)$ & $6(2.6)$ & $\leq 0.001$ \\
\hline $\begin{array}{l}\text { Are you concerned about the lack of } \\
\text { anthropometric measures and vitals in } \\
\text { case patient video-calls from home? }\end{array}$ & $90(38.5)$ & $84(35.9)$ & $33(14.1)$ & $18(7.7)$ & $9(3.8)$ & $\leq 0.001$ \\
\hline $\begin{array}{l}\text { Are you concerned about the limited } \\
\text { comfort with sensitive examination? }\end{array}$ & $69(29.5)$ & $90(38.5)$ & $45(19.2)$ & $18(7.7)$ & 12(5.1) & $\leq 0.001$ \\
\hline
\end{tabular}

Low level of public education, poor knowhow regarding handling technology and lack of infrastructure were considered the main constraints for the public in using telemedicine (Fig.1).

\section{DISCUSSION}

Tele-medicine is a novel technology for the poor third world countries and has a strong potential to bring about quintessential changes 
Table-III: Relation of demographics with availability of basic infrastructure for telemedicine services.

\begin{tabular}{|c|c|c|c|}
\hline Variables & Locality $(p)$ & $\begin{array}{l}\text { Nature of } \\
\text { setup }(p)\end{array}$ & $\begin{array}{l}\text { Specialty of the } \\
\text { participating doctors }(p)\end{array}$ \\
\hline Specific training & 0.28 & 0.003 & $\leq 0.001$ \\
\hline Availability of specific infrastructure & 0.002 & 0.007 & $\leq 0.001$ \\
\hline Availability of specific hardware & 0.06 & 0.01 & $\leq 0.001$ \\
\hline Availability of specific software & 0.008 & $\leq 0.001$ & $\leq 0.001$ \\
\hline Affordability for the set-up & 0.17 & $\leq 0.001$ & $\leq 0.001$ \\
\hline Affordability for the patients & 0.03 & 0.002 & $\leq 0.001$ \\
\hline Means to measure effectiveness of telemedicine services & 0.03 & 0.002 & $\leq 0.001$ \\
\hline Maintenance cost & 0.001 & $\leq 0.001$ & $\leq 0.001$ \\
\hline
\end{tabular}

to healthcare facilities if used wisely. ${ }^{9}$ A systemic review by Bashshur $\mathrm{R}$ et al showed that telehealth services decreased the use of unnecessary antibiotics and re-admissions, increased the return visits at hospitals for necessary followup, increased smoking cessation rate and helped to reduce unnecessary referrals by $40 \%$. Despite all these promising outcomes, mortality was unaffected and the availability of standardized communication facilities did not improve patient attendance. ${ }^{10}$

Many of the participants in our study were not aware of the financial implications and the running/ maintenance costs involved in telemedicine, the phenomenon that was also studied in a local study $^{2}$, proving that our medical community lacks familiarity with latest innovations. Despite the lack of this knowledge, many of the doctors in our study reported that telemedicine is an affordable service for both their set-ups and patients. In contrast, the doctors from specialized medical fields like Gynaecology and Obstetrics, Cardiology, Gastroenterology, Ophthalmology etc believed that tele-health might not be a cost-effective mode, probably because of the sophisticated technology required for evaluation and monitoring.

An emerging concern is the lack of robust studies regarding the cost analysis and its implications on the budgets of lower to middle income countries. ${ }^{11}$ Monitoring of chronic diseases has been historically considered cost-effective but the studies (and consequently the results) are sketchy. ${ }^{12}$ Setting up tele-health facility has been seen to be far more expensive than the running and maintenance cost. ${ }^{7}$ No consensus is available for the cost effectiveness of tele-health ${ }^{7}$ and vigorous studies are required for quality and control.
In our study only the junior doctors (who could be redeployed and were not a part of a specialized unit) and those in Public Health Department reported receiving specific training. The training was also found statistically related to the nature of set-up i.e, the doctors working in larger teaching and tertiary care hospitals reported availability of infrastructure and specific training. The rural and semi-urban set-ups have been studied to benefit more from tele-health, ${ }^{13}$ owing to logistics and funds allocation, but have been largely neglected in the poor counties just like other basic necessaties. ${ }^{14}$ Interestingly, the availability of specific hardware like electronic stethoscopes, ophthalmoscopes and high-quality digital cameras were deficient even in those set-ups that were practicing telemedicine on regular basis which explains the reluctance of specialized fields like Cardiology, Gastroenterology, Dentistry, Ophthalmology etc towards tele-consultations. The specialties including Dermatology, Radiology and preventive medicine did not need these gadgets and reported higher participation with availability of satisfactory framework.

Itwasinteresting toseethatmanyof theparticipants showed their lack of knowledge towards the basic facets of this novel healthcare facility including common care protocols, indemnity, standards for comparison, accreditation of service providers and risks to patient privacy. This illiteracy might be one of the biggest confounders responsible for the reluctance on part of the doctors and lack of prompting for conceivable policies at national level. ${ }^{2}$ An equally large number of doctors were concerned regarding the medico-legal implications associated with missed diagnosis, prescription errors, sensitive examinations and 
lack of anthropometric measures/vitals in our study which could be mitigated by effective triaging, training, redeployment of trained nurses and home monitoring. ${ }^{7,8}$

Acceptability towards an innovative technology has always been the main hurdle not only in the developing country but also the developed ones. ${ }^{15}$ Our study also reported a high resistance to change as perceived by the doctors but the availability of tele-health services in a particular set-up helped to mitigate the fear and confusion among public, making it more acceptable. The same phenomenon was also stated in a systemic review that urged for user friendly interface, incorporating local languages in to the applications and training of the personnel. ${ }^{14}$ This was contradictory to a study from Africa that showed a high acceptance towards tele-psychiatry consultations among women, ${ }^{16}$ making it necessary to conduct larger randomized studies with regional and cultural consideration.

The participating doctors reported lack of literacy and infrastructure as the most devastating elements responsible for poor acceptability of Tele-health at the public level. A similar study demonstrated the effect of poor infrastructure and resources as the main barrier in the development of Tele-medicine in the developing countries of Africa, Americas and the South-East Asia. ${ }^{14}$ This was in contrast to an indigenous study by Ahmed A et al that reported familiarity with technology was not an issue for the adoption of tele-health facilities. ${ }^{2}$

The practice of medicine and healing is intrinsically related to patient's confidentiality, privacy and respect with sensitive examinations requiring utmost consideration and civility. ${ }^{17}$ Though, as many as $91 \%$ of the participants in our study claimed physical exam was necessary for their practice and diagnosis, an equal number were concern regarding the sensitivity of this issue.

Disregard to the local culture, poor training and evaluation systems and lack of continual assistance and guidance are all the major pitfalls common for developing countries. ${ }^{14}$ Telemedicine may not be suitable for all medical conditions and should be used in collaboration with the conventional healthcare facilities. ${ }^{7,18}$ Telemedicine has proven benefit in rapid triaging, tele-education, telerehabilitation, tele-psychiatry, monitoring of chronic diseases and tele-consultations among doctors for specialist opinion. ${ }^{4,7,18}$ Also careful patient triaging is needed for patient satisfaction and ultimately the success of a program. ${ }^{19}$

The greatest strength of this study is a good mix of all specialties with varied experiences, from different set ups and regions of the country as shown in Fig.1. Also rather than testing the basic knowledge of tele-medicine, doctors' point of view regarding the perceived barriers was explored in detail. The limitation of the study is convenience sampling and participants were encouraged to share the survey through email for maximum participation.

\section{CONCLUSION}

Evidence of effectiveness of telemedicine across different fields is inconsistent and lacks technical, legal, cultural and ethical considerations for the developing countries. Inadequate training, low level of technological literacy and lack of infrastructure are the main barriers in implementing tele-health. High quality evidence based studies are required for practical long-term policies.

Source of Funding: None.

Conflict of Interest: None.

\section{REFERENCES}

1. Siegel CA. Transforming Gastroenterology Care with Telemedicine. Gastroenterology. 2017;152(5):958-963. doi: 10.1053/j.gastro.2017.01.048

2. Ahmed A, Ahmed M. The Telemedicine Landscape in Pakistan- Why are we falling behind? J Pak Med Assoc. 2018;68(12):1820-1822.

3. Adler-Milstein J, Kvedar J, Bates DW. Telehealth among US hospitals: several factors, including state reimbursement and licensure policies, influence adoption. Health Aff (Millwood). 2014;33:207-215.

4. Khan UZ. Telemedicine in the COVID-19 Era: A chance to make a better tomorrow. Pak J Med Sci. 2020;36(6):14051407. doi: 10.12669 / pjms.36.6.3112

5. Combi C, Pozzani G, Pozzi G. Telemedicine for developing countries: a survey and some design issues. Appl Clin Inform. 2016;7:1025-1050. doi: 10.4338/ACI2016-06-R-0089

6. Mahajan V, Singh T, Azad C. Using Telemedicine During the COVID-19 Pandemic. Indian J Pediatr. 2020;57(7):658-661.

7. Ekeland A, Bowes A, Flottorp S. Effectiveness of telemedicine: A systematic review of reviews. Int J Med Inform. 2010;79(11):736-771. doi: 10.1016/j.ijmedinf.2010.08.006

8. Iyengar K, Jain V, Vaishya R. Pitfalls in telemedicine consultations in the era of COVID 19 and how to avoid them. Diabetes Metabol Syndr. 2020;14(5):797-799. doi: 10.1016/j.dsx.2020.06.007

9. Harst L, Lantzsch H, Scheibe M. Theories Predicting End-User Acceptance of Telemedicine Use: Systematic Review. J Med Internet Res. 2019;21(5):e13117. doi: $10.2196 / 13117$ 
10. Bashshur R, Howell J, Krupinski E, Harms K, Bashshur N, Doarn C. The Empirical Foundations of Telemedicine Interventions in Primary Care. Telemedicine and e-Health. 2016;22(5):342-375. doi: 10.1089/tmj.2016.0045

11. Jacob C, Sanchez-Vazquez A, Ivory C. Social, Organizational, and Technological Factors Impacting Clinicians' Adoption of Mobile Health Tools: Systematic Literature Review. JMIR Mhealth Uhealth 2020;8(2):e15935. doi: 10.2196/15935

12. Adenuga $K$, Iahad $\mathrm{N}$, Miskon $\mathrm{S}$. Towards reinforcing telemedicine adoption amongst clinicians in Nigeria. Int J Med Inform. 2017;104:84-96. doi: 10.1016/j. ijmedinf.2017.05.008

13. Lopes MACQ, Oliveira GMM, Ribeiro ALP, Pinto FJ, Rey $\mathrm{HCV}$, Zimerman LI, et al. Guidelines on the Brazilian Society of Cardiology on Telemedicine in Cardiology. Arq Bras Cardiol. 2019;113(5):1006-1056. doi: 10.5935/ abc. 20190205

14. Combi C, Pozzani G, Pozzi G. Telemedicine for Developing Countries. Appl. Clin. Inform. 2016;07(04):1025-1050. 10.4338/ ACI-2016-06-R-0089

15. Zailani S, Gilani M, Nikbin D, Iranmanesh M Determinants of Telemedicine Acceptance in Selected Public Hospitals in Malaysia: Clinical Perspective. J Med Syst. 2014;38(9). doi: 10.1007/s10916-014-0111-4

16. McCall T, Schwartz T, Khairat S. Acceptability of Telemedicine to Help African American Women Manage Anxiety and Depression. Stud Health Technol Inform 2019;264:699-703. doi: 10.3233/SHTI190313
17. Chaet D, Clearfield R, Sabin JE, Skimming K. Council on Ethical and Judicial Affairs American Medical Association. Ethical practice in Telehealth and Telemedicine. J Gen Intern Med. 2017;32(10):1136-1140. doi: 10.1007/s11606017-4082-2

18. Cui F, Ma Q, He X, Zhai Y, Zhao J, Chen B, et al. Implementation and Application of Telemedicine in China: Cross-Sectional Study. JMIR Mhealth Uhealth. 2020;8(10):e18426. doi: 10.2196/18426

19. American Well. Telehealth Index: 2017 Consumer Survey. [Internet]. [cited 23 November 2020]. Available from: http://go.americanwell.com/rs/335-QLG-882/images/ American_Well_Telehealth_Index_2017_Consumer_ Survey.pdf

\section{Author's Contribution:}

LA: Contributed to the idea, questionnaire, data collection, literature review, statistical analysis and drafting the manuscript.

MA: Contributed to data collection and questionnaire.

AM, VF: Contributed to data collection.

All the authors take equal responsibility for the accuracy and integrity of the work.
Authors:

1. Laima Alam, FCPS

Consultant Gastroenterology,

Bahria Town International Hospital, Rawalpindi, Pakistan.

2. Mafaza Alam

Registrar Operative Dentistry, Armed Forces Institute of Dentistry,

Rawalpindi, Pakistan.

3. Amina Mannan Malik

Shifa International Hospital, Islamabad, Pakistan.

4. Varqa Faraid

Shaheed Zulfiqar Ali Bhutto Medical University,

School of Dentistry,

Islamabad, Pakistan. 